\title{
Experimental and numerical investigation of aluminium lap joints made by RFSSW
}

\author{
Piotr Lacki • Anna Derlatka
}

Received: 6 January 2015/ Accepted: 31 October 2015/Published online: 16 November 2015

(C) The Author(s) 2015. This article is published with open access at Springerlink.com

\begin{abstract}
Friction stir welding is one of the newest methods of metal welding. The method is constantly being developed and friction stir spot welding (FSSW) is one of its varieties. The method is mainly used in the aircraft, automotive and shipbuilding industries. During the process, heat is generated as a result of friction between the tool and materials as well as plastic deformation of the joined materials. The paper presents a numerical analysis of welded structures made of 6061-T6 aluminium alloy. The specimens were joined by refill FSSW. This method joins metals in a solid state. The numerical calculations were performed using the ADINA System based on the finite element method. The sheets were modelled with shell elements and the joints were modelled with 3Dsolid elements. The experimental investigations were carried out using a non-contact system allowing for measuring displacements and strains in real time. The numerical results were compared with the test ones. The structures were assessed regarding strength and the possibility of their application in the aircraft industry.
\end{abstract}

Keywords Finite element method A Aluminium 6061-T6 · Refill friction stir spot welding (RFSSW)

P. Lacki $(\bowtie) \cdot$ A. Derlatka

Czestochowa University of Technology,

Dąbrowskiego 69, 42-201 Czestochowa, Poland

e-mail: piotr@lacki.com.pl

\section{Introduction}

Refill friction stir spot welding (RFSSW) is solid-state joining technology which is characterized by reliability, safety and the fact that it is not very timeconsuming. This process is a more recent application of the friction stir welding (FSW) process. RFSSW could be used for materials not recommended for fusion welding i.e. aluminium alloys (especially 2XXX and 7XXX alloy series) or titanium [1]. This technology along with other modern joining methods (e.g. electron beam welding, laser welded joint, riveting and hybrid joints: spot welding-adhesive) are of great technological interest [2-7].

In RFSSW, a specially designed rotating tool (Fig. 1) is used to create the weld spot. The tool is plunged into the workpieces to plasticize and mix the material. Heat is generated by frictional forces and due to deformation of the parent material [8].

To introduce the tool design, select process parameters, predict void formation, and simulate material flow, FEM models could be used. The first approach of numerical analysis is the thermo-mechanical model. Most thermal analyses use a heat source distributed over the tool surface, with a heat flux per unit area. The heat is generated at the interface by friction or by viscous dissipation in a layer that is sufficiently thin. In a different approach, the heat input may be distributed over the probe volume. Such approximations lose significance as the distance from the heat source 

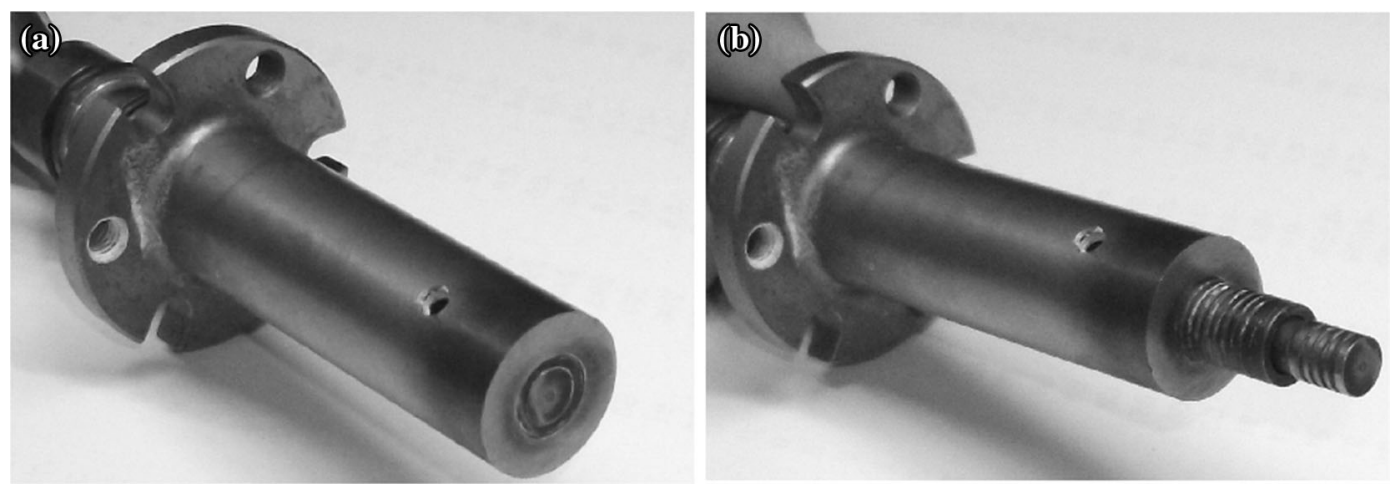

Fig. 1 Tool for RFSSW process: a during plunging and retraction steps, b after plunging into workpieces

increases due to heat flow problems. The next assumption is usually to ignore tool tilt and the effect of metal flow on the distribution of heat generation. The source is treated as axisymmetric. The smooth circumferential distribution of heat is the consequence of the high rotational speed and convective heat flow by motion of the material $[9,10]$. Computation of the thermo-mechanical fields during all the FSW phases (plunge, friction, retraction) without information about the process, only relying on accurate constitutive and friction models, is presented in [11, 12]. Based on the numerical and experimental investigations, the results of the model are found to be very sensitive to small variations of the friction coefficient. The study of the different process conditions shows that the main phenomena taking place during FSW can be simulated with the right sensitivities. Based on further analysis presented in [13], a valid model to determine the strength and temperature of the tool were constructed.

Another method for modelling structures welded by FSW is mechanical analysis. In [14] the analysis of stiffened panel structures with a friction stir weld was carried out. The base material and weld were modelled as 3D-solid elements. The difference of geometry after the welding process and properties of the materials were included. There is a high computational cost associated with full a 3D-solid model. Very finite meshes may need to be used and large strain shell problems can be complicated to solve [15].

For shorter modelling and computational times, 3D-shell elements are used. The three-dimensional continuum theory is shorter compared to a full threedimensional analysis. It is important if many different configurations have to be analysed during the initial design phase of the structure. It is possible to model the RFSSW spot and heat affected zone (HAZ) as 3Dsolid elements and the sheet base material as shell elements [16]. A comparison of three types of models was presented in [17]. A full 3D-solid model is the most exact, but it might be used only for small constructions. The restrictions are the long total solution time and computer requirements. The full shell model or 3D-shell model could be used for preliminary calculations to determine the weakest area in the structure or for large structures. Papers [18, 19] present the analysis of complex structures with 3Dsolid elements for the weld spots and shell elements for the sheets.

\section{Goal and scope of work}

Determining crack locations by numerical and experimental analyzes of RFSSW joints during the tensile test is the goal of this paper. The structures were assessed regarding tensile strength, strains and deformations. 6061-T6 aluminium alloy sheets are welded as lap joints. Two types of geometry with four and five RFSSW spots are analysed-Figs. 2 and 3. Each sample is modelled as a full 3D-solid model. The numerical results are compared with the experimental investigation which was carried out using a noncontact system allowing for measuring displacements and strains in real time.

The surface area of spots in the sample with four and five RFSSW spots are respectively 208.23 and $271.85 \mathrm{~mm}^{2}$. The RFSSW process were made with 
Fig. 2 Geometry of sample with four RFSSW spots, $\mathrm{mm}$
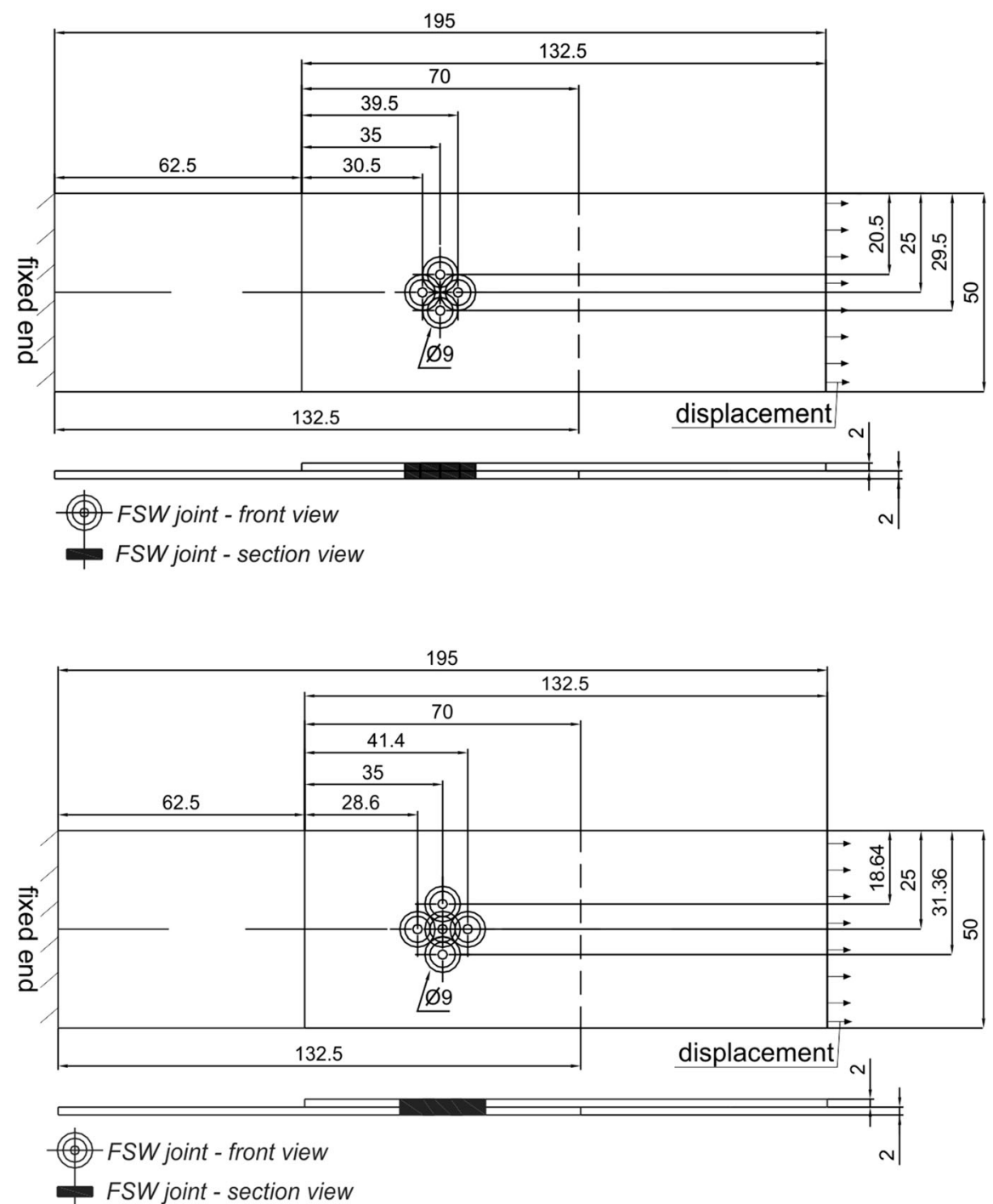

Fig. 3 Geometry of sample with five RFSSW spots, $\mathrm{mm}$ curve for the sample with five spots is longer due to the larger surface area of the spot group.

The strain distribution for the analysed samples are presented in Fig. 5. The distributions are symmetrical with respect to the vertical axis (Z-axis). In each sample, the area of maximum value concentration is located on the edge of the spot group and base material, where the sample fractures are Fig. 6.

\section{Computational models}

The numerical studies were carried out with the ADINA System based on the FEM. The boundary 
Fig. 4 Displacement-force diagram

Fig. 5 Samples during tensile test: a strain distribution for four RFSSW spots, b strain distribution for five RFSSW spots

Fig. 6 Samples after the tensile test: a four RFSSW spots, a five RFSSW spots

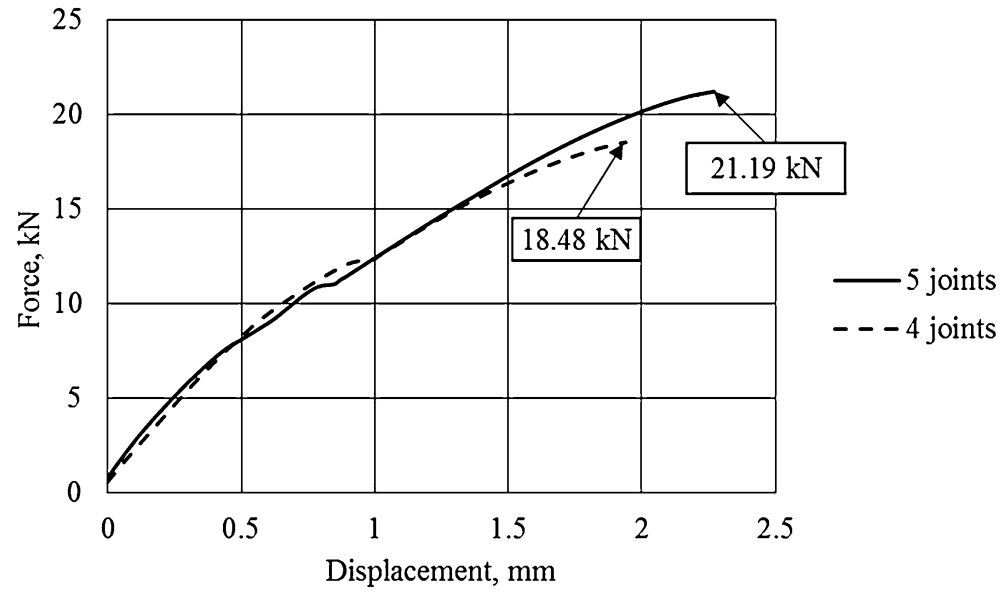

(a)

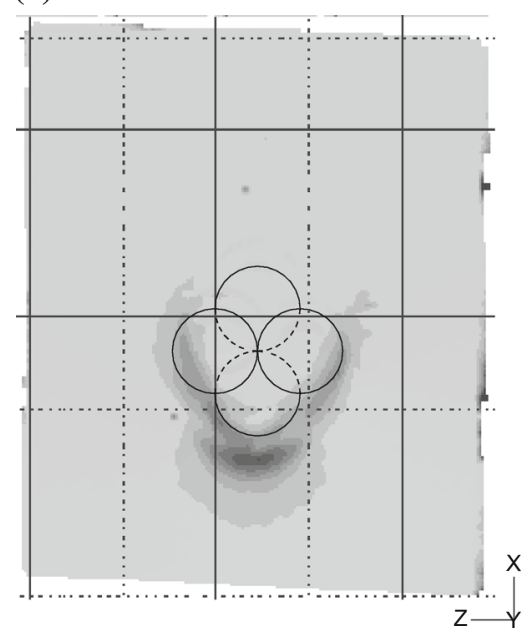

(b)

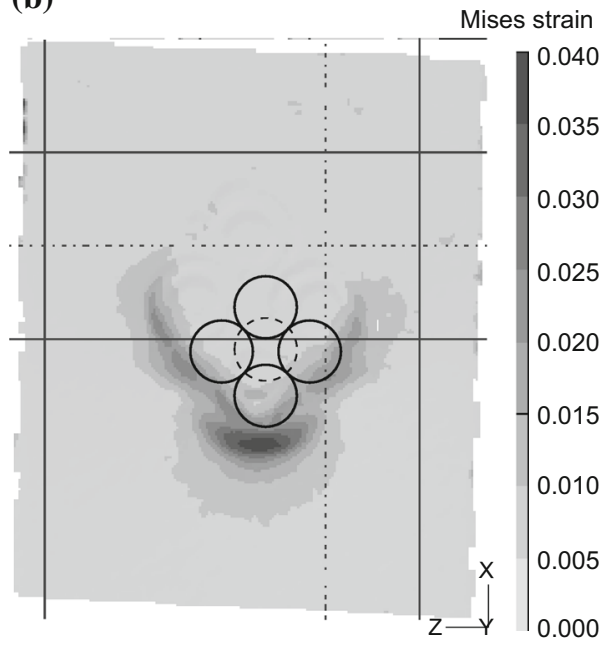

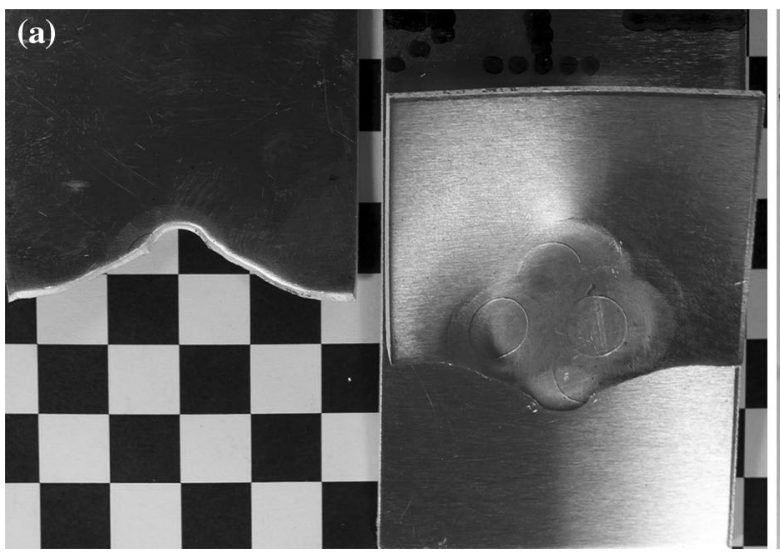

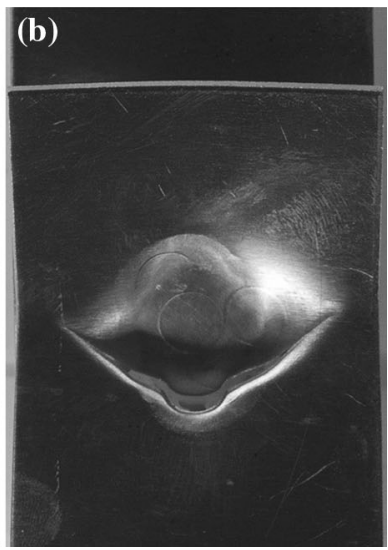


conditions and type of load are the same for each sample: all the degrees of freedom on the first external edge of the sample are fixed, the second external edge of the sample has one free degree of freedom (Xtranslation) and that edge is loaded by displacement. The load values are equivalent to the displacements which were reached during the experiments. Plastic orthotropic material with following parameters: modulus of elasticity $68.9 \mathrm{GPa}$, yield strength $276 \mathrm{MPa}$, Poisson's ratio 0.33 and density $2700 \mathrm{~kg} / \mathrm{m}^{3}$, are used for each model. The meshes of the samples are shown in Figs. 7 and 8.

The sheets and spots are modelled as 8-node 3Dsolid elements. Between the 3D element surfaces of the sheets, the contact conditions are assumed. The sheet and spot elements are connected in nodes. The boundary conditions and load are added to the surfaces. The model with four RFSSW spots is comprised of 27,851 3-D solid elements, which is equivalent to 22,176 nodes. The model with five spots is comprised of 34,272 finite elements, which is equivalent to 32,735 nodes. The calculations are performed in 100 time steps.

\section{Results}

The total solution time for the sample with four RFSSW spots was $1794.40 \mathrm{~s}$. The total memory used by the program for that model was $525.3 \mathrm{mb}$. However, the total solution time for the sample with five RFSSW spots was $2488.85 \mathrm{~s}$ and total memory used by the program for that model was $640.4 \mathrm{mb}$.

The effective plastic strains for the samples with four and five spots are presented in Figs. 9 and 10 respectively.

In both samples, the plastic effective strains distributions are symmetrical with respect to the $\mathrm{X}$-axis and similar in both sheets. In each kind of sample, the strain maximum is located on the inner side of the sheet surrounding the RFSSW spots, on the part which is fixed. The extreme values are concentrated on the inner sides of the spots, which is difficult to specifically identify. The minimum is also located on the inner side of the sheet surrounding the RFSSW spots, but on the part which is free.

The Y-displacement and deformations for the samples with four and five spots are presented in Figs. 11 and 12. (a)

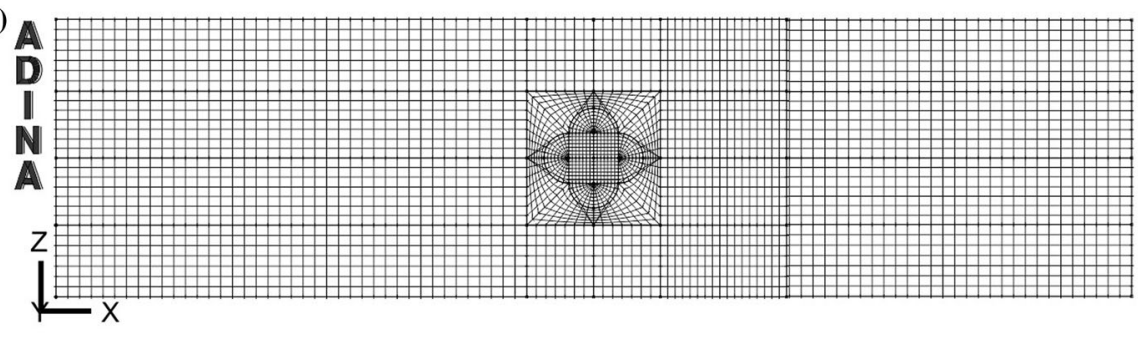

(b)

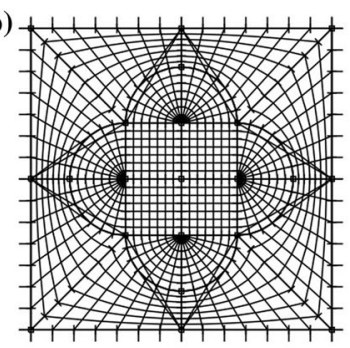

Fig. 7 Mesh of sample with four spots: a whole model view, b RFSSW spots view

(a)

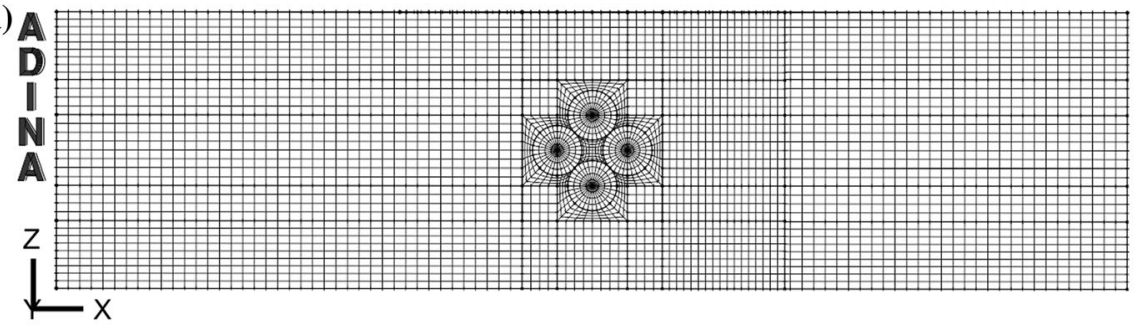

(b)

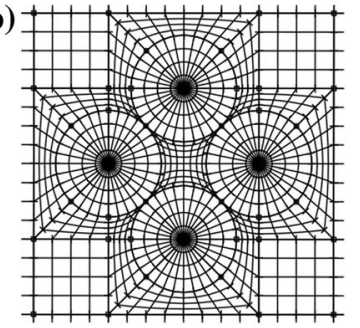

Fig. 8 Mesh of sample with five spots: a whole model view, b RFSSW spots view 
Fig. 9 Effective plastic strains for sample with four spots: a X-Z view, b X-Y view, mag. $\times 5$
Fig. 10 Effective plastic strains for sample with five spots: a $X-Z$ view, b axonometric view, mag. $\times 5$
Fig. 11 Y-displacement $(\mathrm{mm})$ and deformations for the sample with four spots, mag. $\times 5$
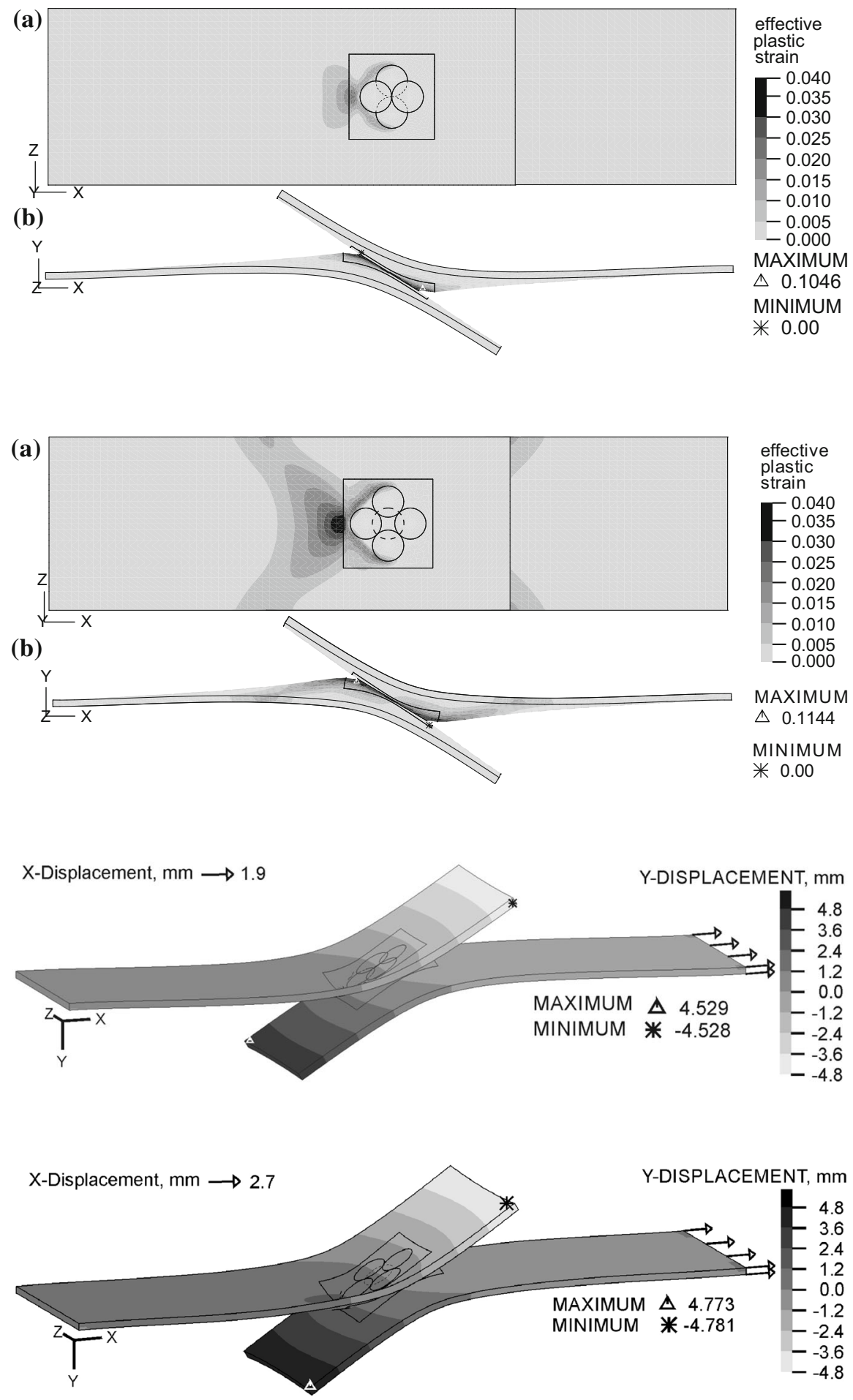

Fig. 12 Y-displacement $(\mathrm{mm})$ and deformations for the sample with five spots, mag. $\times 5$ samples with four and five spots are 4.5 and $4.7 \mathrm{~mm}$. Furthermore, the deformation is near the welded area. 


\section{Discussion}

The higher strength of the sample with five RFSSW spots than the sample with four spots is caused by the larger surface area of the spots group. The shape of the tensile curve is similar for both samples. It proves the similar behaviour of the structures. In each of the analysed cases, the fracture is on the edge of the spots and base material. In accordance with articles [20-22] the spot welds in the groups are not separated from each other, nor from the sheets, as in the case of welding by a single spot joint.

The experimental and numerical analyses prove that regardless of the joint geometry, the strains concentration is in the area of the base material near the RFSSW spots. It indicates the places of fracture initiation.

The deformations of sheets parts are the result of non-fixed edges with respect to the Y-axis. The deformation of the welded area is caused by the strength of the joints and deflections of the sheets.

\section{Conclusion}

The analysis of RFSSW joints with different numbers and spot arrangement of are investigated. The following conclusions were made:

- It is possible to model those joints as 3D-solid elements. Good agreement is observed with the specimens compared to the experimental results.

- The strength of the sample with five RFSSW spots is higher than the sample with four RFSSW spots.

- In the each sample, the strains concentration is observed on the outer edge of the spots, between the inner surfaces of the sheets.

- In each case, the fracture is on the edge of the spots and base material. The spot welds in the groups are not separated from each other, nor from the sheets.

- The free parts of sheets are deflected with respect to the Y-axis.

Acknowledgments Financial support of Structural Funds in the Operational Programme-Innovative Economy (IE OP) financed from the European Regional Development FundProject "Modern material technologies in aerospace industry", Nr POIG.01.01.02-00-015/08-00 is gratefully acknowledged.
Open Access This article is distributed under the terms of the Creative Commons Attribution 4.0 International License (http:// creativecommons.org/licenses/by/4.0/), which permits unrestricted use, distribution, and reproduction in any medium, provided you give appropriate credit to the original author(s) and the source, provide a link to the Creative Commons license, and indicate if changes were made.

\section{References}

1. Lacki P, Derlatka A (2013) The application of FSW technology in aluminium structures. Met Form 24:205-218

2. Lacki P, Adamus J, Wieckowski W, Winowiecka J (2013) Evaluation of drawability of titanium welded sheets. Arch Metall Mater 58(1):139-143

3. Tu HY, Schmauder S, Weber U, Rudnik Y, Ploshikhin V (2011) Numerical simulation and experimental investigation of the damage behavior on electron beam welded joints. Proc Eng 10:875-880

4. Tu HY, Schmauder S, Weber U, Rudnik Y, Ploshikhin V (2013) Simulation of the damage behaviour of electron beam welded joints with the Rousselier model. Eng Fract Mech 103:153-161

5. Tu HY, Schmauder S, Weber U (2014) Numerical simulation of crack propagation in Al6061 laser welded joints. Proc Mater Sci 3:414-420

6. Sadowski T, Kneć M, Golewski P (2010) Experimental investigations and numerical modelling of steel adhesive joints reinforced by rivets. Int J Adhes Adhes 30(5):338-346

7. Sadowski T, Balawender T, Sliwa R, Golewski P, Knec M (2013) Modern hybrid joints in aerospace: modelling and testing. Arch Metall Mater 58(1):163-169

8. Lacki P, Kucharczyk Z, Śliwa RE, Gałaczyński T (2013) Effect of tool shape on temperature field in friction stir spot welding. Arch Metall Mater 58(2):597-601

9. He X, Gu F, Ball A (2014) A review of numerical analysis of friction stir welding. Prog Mater Sci 65:1-66

10. Mishra RS, Mahoney MW (2007) Friction stir welding and processing. ASM International, Materials Park

11. Fourment L, Guerdoux S (2008) 3D numerical simulation of the three stages of friction stir welding based on friction parameters calibration. Int $\mathrm{J}$ Mater Form 1(1):1287-1290

12. Guerdoux S, Fourment L (2009) A 3D numerical simulation of different phases of friction stir welding. Model Simul Mater Sci Eng 17(7):1-32

13. Assidi M, Fourment L, Guerdoux S, Nelson T (2010) Friction model for friction stir welding process simulation: calibrations from welding experiments. Int $\mathbf{J}$ Mach Tool Manuf 50:143-155

14. Yoon JW, Bray GH, Valente R, Childs T (2009) Buckling analysis for an integrally stiffened panel structure with a friction stir weld. Thin Wall Struct 47(12):1608-1622

15. Tutunchilar S, Haghpanahi M, Besharati Givi MK, Asadi P, Bahemmat P (2012) Simulation of material flow in friction stir processing of a cast Al-Si alloy. Mater Des 40:415-426 
16. Fanelli P, Vivio F, Vullo V (2012) Experimental and numerical characterization of friction stir spot welded joints. Eng Fract Mech 81:17-25

17. Derlatka A, Kudła K, Makles K (2014) Numerical analysis of RFSSW joints. In: Oñate E, Oliver X, Huerta A (eds) 11th World congress on computational mechanics (WCCM XI), Barcelona

18. Derlatka A, Kasza P (2014) Numerical analysis of aluminium cellular beams with cells of different diameters. Adv Mater Res 1020:151-157

19. Derlatka A, Kasza P (2014) Numerical analysis of aluminum cellular beams with cells of different arrangement. Adv Mater Res 1020:158-164
20. Sadowski T, Golewski P, Kneć M (2014) Experimental investigation and numerical modelling of spot weldingadhesive joints response. Compos Struct 112:66-77

21. Sadowski T, Kneć M, Golewski P (2014) Spot weldingadhesive joints: modelling and testing. J Adhes 90(4):364

22. Sadowski T, Golewski P, Zarzeka-Raczkowska E (2011) Damage and failure processes of hybrid joints: adhesive bonded aluminium plates reinforced by rivets. Comput Mater Sci 50(4):1256-1262 